\title{
Ensino de sintaxe na educação básica: um estado da arte do cenário brasileiro
}

\author{
Mário Martins \\ Universidade Federal Rural do Semi-Árido (UFERSA) \\ mario.martins@ufersa.edu.br
}

Marielly Pereira

Programa de Pós-Graduação em Ensino (POSENSINO)

Universidade Federal Rural do Semi-Árido (UFERSA)

mariellypsousa@gmail.com

\section{Resumo}

Neste artigo, tem-se por objetivo analisar, a partir de um estado da arte, a pesquisa em ensino de sintaxe na educação básica brasileira. O ensino de sintaxe constitui uma pauta de debate acadêmico, sustentando-se frequentemente na oposição entre convicções linguísticas e prescrições gramaticais. Nesse cenário de disputa, justifica-se explorar o papel das investigações científicas e, consequentemente, questionar-se sobre o que se tem discutido a respeito do ensino de sintaxe. $\mathrm{O}$ Catálogo de Teses e Dissertações, o Portal de Periódicos e ainda o Google Acadêmico são as bases de dados deste estado da arte. Os resultados indicam que grande parte da pesquisa sobre o ensino de sintaxe é de natureza propositiva, de orientação funcionalista e/ou descritivista, com foco nos complexos oracionais e com fins para o incremento das competências linguísticas dos alunos da educação básica.

Palavras-chave: Ensino de sintaxe. Ensino de gramática. Educação básica.

\begin{abstract}
Based on a state of the art, this study aims to present an analysis of research on the teaching of syntax in Brazilian basic education. The teaching of syntax promotes a continuous academic debate, often based on the opposition between linguistic convictions and grammatical prescriptions. In this dispute scenario, it is justified to explore the role of scientific investigations and, consequently, to question about what has been discussed regarding the teaching of syntax. The Catalog of Theses and Dissertations, the Portal of Journals and also the Google Scholar are the databases of this state of the art. The results indicate that much of the research on the teaching
\end{abstract}


of syntax is of a propositional nature, with a functionalist and/or descriptive orientation, with a focus on clause complexes and with the purpose of increasing the linguistic competences of basic education students.

Keywords: Syntax teaching. Grammar teaching. Basic education.

\section{Introdução}

O ensino de gramática da língua materna tem sido, no amplo cenário educacional brasileiro, um tema de debate bastante vivo nas últimas décadas, com adeptos em cada uma das diversas e, muitas vezes divergentes, perspectivas teóricas e empíricas que dão substância a esse debate. A despeito das várias camadas de detalhes que esse debate possa ter, é possível sintetizar que o mote da crítica se erige contra um modelo de ensino de gramática que é voltado para a transmissão de terminologias e de seus conceitos, o que se materializa em exercícios de classificação e identificação de formas e definições, com exemplos descontextualizados, e sempre com fins prescritivos.

Apesar de, nas décadas de 70 e 80, já serem significativas as contribuições dos estudos linguísticos para o ensino - nessas décadas já circulavam, por exemplo, discussões sobre variedades linguísticas, concepções descritivistas de língua e a centralidade do texto (MALFACINI, 2015), a crítica ao ensino anacrônico de gramática passou a tornar-se uma realidade bastante palpável nas práticas das salas de aula brasileiras no final da década de 90, com a publicação dos Parâmetros Curriculares Nacionais para o ensino de Língua Portuguesa (BRASIL, 1998). Nascido das propostas de uma reforma ampla para a educação básica estabelecidas na Lei de Diretrizes e Bases da Educação Nacional (LDB), promulgada em 20 de dezembro de 1996 (BRASIL, 1996), os PCN lançam luz ao conceito de competência discursiva, em que o texto (ou o gênero de texto) é "a unidade básica do ensino" (p. 23), portanto opondo-se à "excessiva valorização da gramática normativa" ou a um ensino baseado em "uma teoria gramatical inconsistente" (p. 18).

Ainda na esteira de uma reforma ampla, a LDB refere-se explicitamente à necessidade da existência de uma base de conteúdo comum a todo o país e que, de algum modo, unifique a educação básica brasileira, o que se tornou realidade com a homologação da Base Nacional Curricular Comum (BRASIL, 2018). A homologação da BNCC deu ignição a inúmeros 
debates novos, mas requentou alguns. Esse é o caso da importância do ensino de gramática na educação básica, reinserido na BNCC sob o nome de análise linguística/semiótica. Enquanto eixo de tratamento das práticas discursivas, instrumentaliza-se a aprendizagem da gramática para a produção/compreensão de textos em práticas de leitura, escuta e produção por meio de um largo conjunto de conteúdos linguísticos e paralinguísticos que devem ser acionados a partir da "análise e avaliação consciente (...) das materialidades" que compõem esses textos (BRASIL, 2018, p. 80), o que inclui, por exemplo, aspectos relacionados à coerência, coesão, progressão temática, ortografia, ritmo, gestualidade ou ainda a aspectos morfológicos, sintáticos ou sociolinguísticos.

O brevíssimo histórico feito até aqui sobre a centralidade do ensino de gramática permite concluir, ecoando Bagno (2003), que não há mais espaço para um ensino de gramática orientado pela tradição gramatical normativista, mas também permite concluir que esse debate se reposiciona ao longo do tempo, conforme as ideias linguísticas também se reposicionam e, por isso, mais uma vez lembrando Bagno, não se pode ignorar a produção científica no campo da linguística para o ensino de gramática da língua materna, razão por que este estudo objetiva sistematizar, a partir de um estado da arte, investigações que o campo de conhecimento linguístico tem ofertado à discussão sobre o ensino de gramática nas salas de aula da educação básica brasileira.

Mais particularmente, nosso interesse de pesquisa centra-se na sistematização da produção de conhecimento científico sobre o ensino de sintaxe - tanto relacionado aos recortes de conteúdos e fundamentos teóricos, como aos recortes de procedimentos de aplicação - nas salas de aula da educação básica. Para tanto, segue-se em linha com o que discutem Faraco e Castro (1999), Myhill, Jones, Lines e Watson (2012) ou Costa e Batalha (2019), por exemplo, quanto à didatização e ao problema da validação das propostas decorrentes da investigação e da disseminação de resultados sobre o ensino de gramática. É, portanto, um trabalho que abre espaço para que um debate sobre correspondências (ou a ausência de) entre o que se tem produzido no contexto investigativo nacional e o que orientam os documentos diretores.

Para este estado da arte nomeadamente, buscou-se, em três plataformas distintas (Google Acadêmico, Catálogo de Teses e Dissertações e Portal de Periódicos da Capes), por pesquisas publicadas entre 1996, ano de implementação dos Parâmetros Curriculares Nacionais (PCN), e 2018, 
ano de publicação da terceira edição da BNCC. A escolha pelo ano de publicação dos PCN enquanto marco temporal inicial se justifica no fato de esse documento nacional ser um divisor de águas na história da educação brasileira, tanto quanto a BNCC parece sê-lo.

\section{Percurso metodológico}

De acordo com Romanowski e Ens (2006), os estudos denominados de estado da arte são aqueles que objetivam a sistematização da produção numa determinada área do conhecimento nos diferentes aspectos que geraram as produções, não se restringindo apenas "a identificar a produção, mas analisá-la, categorizá-la e revelar os múltiplos enfoques e perspectivas" (p. 39). Trata-se, portanto, de uma pesquisa de caráter descritivo, com método de análise quantitativo e/ou qualitativo e que visa compreender um fenômeno em suas diversas dimensões dentro de uma área investigativa. Expõe-se, assim, um "universo de significados, motivos, aspirações, crenças, valores e atitudes, o que corresponde a um espaço mais profundo das relações, dos processos e dos fenômenos que não podem ser reduzidos à operacionalização de variáveis" (MINAYO, 2002, p. 22). Crê-se, portanto, que um estado da arte rigoroso possa lançar luz nas pautas por nós levantadas sobre o ensino de sintaxe na educação básica.

Para este estado da arte, realizou-se uma busca por artigos (em periódicos ou em anais), teses, dissertações, livros ou capítulos de livros nas seguintes bases de dados: Catálogo de Teses e Dissertações e Portal de Periódicos, ambos pertencentes à Coordenação de Aperfeiçoamento de Pessoal de Nível Superior (CAPES), e no Google Acadêmico. Como primeiro critério de busca, estabeleceram-se buscas delimitadas pela faixa temporal entre 1996 e 2018. ${ }^{1}$ Trata-se do período entre a implementação dos PCN e a última versão homologada da BNCC, que se caracteriza como um período significativo para a consolidação ou mudança de paradigmas de ensino. Trata de um período de grandes transformações no ensino da língua portuguesa, especificamente no ensino da gramática.

Quanto aos descritores de busca, inicialmente foram escolhidos ensino de sintaxe ou ensino da sintaxe em combinação com ensino

${ }^{1}$ Vale destacar que, no Portal de Periódicos da CAPES, há dados disponíveis apenas a partir de 2001. 
fundamental ou ensino médio. Justificava-se usar descritores relacionados aos níveis de ensino para excluir, à partida, trabalhos cujo escopo fossem o ensino de sintaxe no nível superior. No entanto, em ambas as plataformas da CAPES, pela aplicação do primeiro cluster de busca (ensino de sintaxe OR ensino da sintaxe AND ensino fundamental), muito poucos trabalhos foram identificados, a saber: 6 trabalhos no Catálogo de Teses e Dissertações e nenhum no Portal de Periódicos. Assim, nessas plataformas, optou-se por eliminar os descritores ensino fundamental e ensino médio. Da nova busca, com apenas um descritor e sua variação (ensino de sintaxe OR ensino da sintaxe), houve os seguintes resultados: 16 dissertações de mestrados e 5 artigos e livros e/ou capítulos de livros. Apenas um trabalho de todos os resultados nas duas plataformas não se encaixava na faixa temporal definida, resultando em 15 dissertações de mestrados e 5 livros e/ou capítulos de livros.

No Google Acadêmico, usando-se o mesmo descritor (ensino de sintaxe OR ensino da sintaxe) e tendo sido aplicado o critério temporal, foram obtidos 193 resultados. Desses resultados, excluíram-se ocorrências de citações e patentes, com restrição de busca apenas a páginas em português, de que se teve, ao final, 161 resultados.

Na sequência, deu-se início ao processo de seleção mais refinado, já centrado na leitura dos títulos, resumos e palavras-chave - enquanto escopo de análise - a fim de se suprimirem i) os trabalhos cujo tema não se centrasse claramente no ensino de sintaxe na educação básica, como, por exemplo, os trabalhos em que, apesar de referirem, de algum modo, o ensino de sintaxe, o ultrapassassem, com a inclusão de outras áreas de conhecimento linguístico; ii) os trabalhos que se referissem a outras realidades que não a brasileira ou que tratassem do ensino de português como língua adicional ou em outros níveis de ensino que não o básico; (iii) os trabalhos cujo gênero de texto não se enquadrasse no perfil delimitado, tais como projetos pedagógicos de cursos ou quaisquer outros documentos não acadêmicos; iv) os trabalhos que ocorressem em duas ou mais plataformas e ainda v) os trabalhos que não fossem acessíveis na internet. Do Portal de Periódicos, 2 trabalhos foram excluídos; do Catálogo de Teses e Dissertações, 10; do Google Acadêmico, 112, sendo selecionados para compor este estado da arte, ao final, 52 publicações científicas.

Aplicamos à seleção final de trabalhos categorias de análise que nos permitiram extrair informações basilares para compor o quadro pretendido sobre o ensino da sintaxe no Brasil. A primeira categoria a orientar nosso 
estado da arte - e tomada como eixo central - foi a abordagem investigativa assumida nos estudos sob apreciação, que elencamos como propositiva, diagnóstica ou interventiva. Nomeamos de abordagem propositiva estudos que, por meio de análise bibliográfica e/ou documental (documentos diretores, livros didáticos, gramáticas, corpora, etc.), oferecem reflexões para novas possibilidades de tratamento da sintaxe - ou de algum tópico específico -, no contexto da disciplina de língua portuguesa na educação básica, seja pela apresentação de novas formas de tratamento teórico dos fatos, seja pela proposta de agregação de novas finalidades para esses fatos.

Definimos como estudos de abordagem diagnóstica aqueles que apresentam descrições de um dado fenômeno sintático (ou um conjunto deles) orientados para práticas de ensino ou de elaboração de recursos didáticos, contudo sem apresentar proposições explícitas. Os estudos aqui definidos como interventivos aplicam as suas proposições (sustentadas em análises bibliográficas e/ou documentais ou ainda a partir de diagnósticos) em contextos quer de prática de sala de aula da disciplina de Língua Portuguesa, quer de formação de professores dessa disciplina. Essas intervenções tipicamente se materializam por meio de oficinas.

Além da abordagem, como descrita acima, instiga-nos também saber quais fatos sintáticos são mais recorrentemente tratados nessas pesquisas e por quais teorias linguísticas tais fatos são mais comumente descritos e interpretados. Por fim, interessa-nos ainda identificar a finalidade que esses estudos defendem para a aquisição do conhecimento sintático.

Essas categorias de análise (abordagem investigativa, fatos sintáticos, teorias linguísticas e finalidade da apropriação do conhecimento) orientaram não somente o percurso metodológico, como também a apresentação dos resultados e da discussão, o que se expõe na seção a seguir.

\section{Resultados e discussão}

Apresentam-se, primeiramente, os resultados de natureza quantitativa obtidos a partir da categorização das pesquisas conforme as categorias previamente definidas: abordagem investigativa, fato sintático, teoria linguística e finalidade da apropriação do conhecimento. De seguida, apresentamos, guiados pelo eixo das abordagens, algumas das pesquisas sobre o ensino de sintaxe que bem ilustram as categorias de análise. 
Assim, quanto à primeira pergunta estabelecida para caracterizar os estudos selecionados, nomeadamente sobre qual a abordagem da pesquisa (se propositiva, diagnóstica ou interventiva), identificou-se que a maioria das pesquisas selecionadas se configura como estudos de abordagem propositiva $(n=34)$. Essa maioria é secundada por pesquisas centradas na realização de diagnósticos quanto ao ensino de sintaxe $(n=11)$. Em terceiro lugar, identificaram-se pesquisas que se propõem a realizar intervenções pedagógicas para comprovar suas inquietações investigativas $(n=7)$. A Figura 1, a seguir, ilustra, com valores percentuais, a distribuição das pesquisas selecionadas quanto à abordagem investigativa por elas assumida:

Figura 1. Distribuição das pesquisas conforme a abordagem (em valores percentuais)

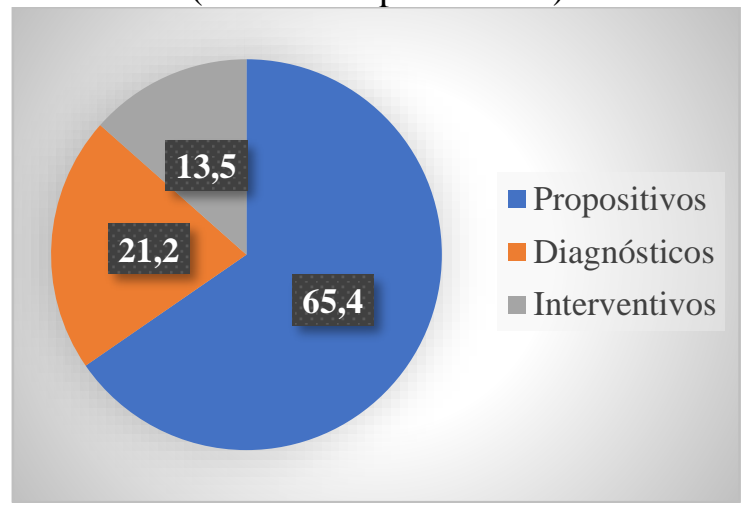

Fonte: elaborado pelos autores

Algumas das pesquisas propositivas esquadrinham como um determinado fato sintático tem sido abordado no ensino e, em alguns casos por meio de diagnósticos, apontam para as principais dificuldades enfrentadas pelos alunos, razão por que sugerem um ensino baseado em uma dada teoria linguística ou em gramáticas não-normativas, o que se aplicaria tanto às práticas de sala de aula, como à reelaboração de materiais didáticos e mesmo de gramáticas escolares.

Quanto às pesquisas diagnósticas, é expressivo que predomine entre elas um tratamento de cunho bibliográfico (e/ou documental), em que se analisam materiais didáticos usados em sala de aula, em que se compara o que está posto em gramáticas escolares e em livros didáticos ou ainda em 
que se comparam gramáticas de diversos tipos ou abordagens gramaticais e linguísticas. Também foram identificadas pesquisas diagnósticas com análise de corpus de atividades escolares ou de textos produzidos por alunos, embora menos recorrentemente.

Por fim, as pesquisas que, neste estado da arte, se caracterizam como de intervenção são as menos acionadas. Tais abordagens, a partir de uma gama diversa de teorias linguísticas, erigem-se como testagem de métodos de ensino, tipicamente por meio de sequências didáticas no contexto de oficinas. Os estudos interventivos aqui obtidos, em sua grande maioria, originam-se de programas de pós-graduação. Para justificar as intervenções, essas pesquisas também apresentam análises bibliográficas e documentais acerca do ensino de sintaxe presente em salas de aula brasileiras.

Sobre os fatos linguísticos acionados, a segunda categoria de análise, há grande variedade, mas destacam-se numericamente os estudos que incidem nas particularidades do período composto $(n=15)$. Igualmente, destacam-se os estudos que não informam explicitamente um tema em particular, referindo apenas que tratam do ensino da sintaxe em geral $(n=15)$. O terceiro fato sintático mais recorrente nos estudos selecionados tem a ver com os limites da frase $(n=11)$. Há ainda pesquisas sobre a pontuação $(n=5)$ e sobre os fenômenos da concordância, colocação e regência $(n=3)$, como se pode visualizar na Figura 2, a seguir, com valores percentuais:

É ampla a gama de perspectivas teóricas adotadas nos estudos, embora despontem quer as pesquisas que assumidamente se enquadram em perspectivas linguísticas funcionalistas $(n=10)$, quer aquelas que se apropriam de gramáticas descritivas $(n=10)$. É também expressiva a quantidade de estudos que não explicitam nem nos títulos, nem nos resumos, nem nas palavras-chave, o arcabouço teórico em que se apoiam $(n=8)$. A Figura 3 ilustra a distribuição das perspectivas teóricas do corpus aqui estudado. 
Ensino de sintaxe na educação básica...

Figura 2. Distribuição das pesquisas conforme o fato sintático (em valores percentuais)

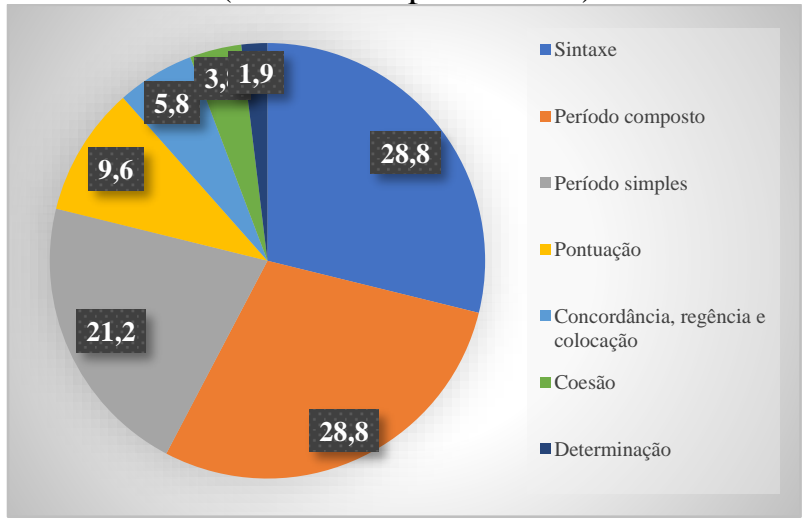

Fonte: Elaborado pelos autores

Figura 3. Distribuição das pesquisas conforme a perspectiva teórica (em valores percentuais)

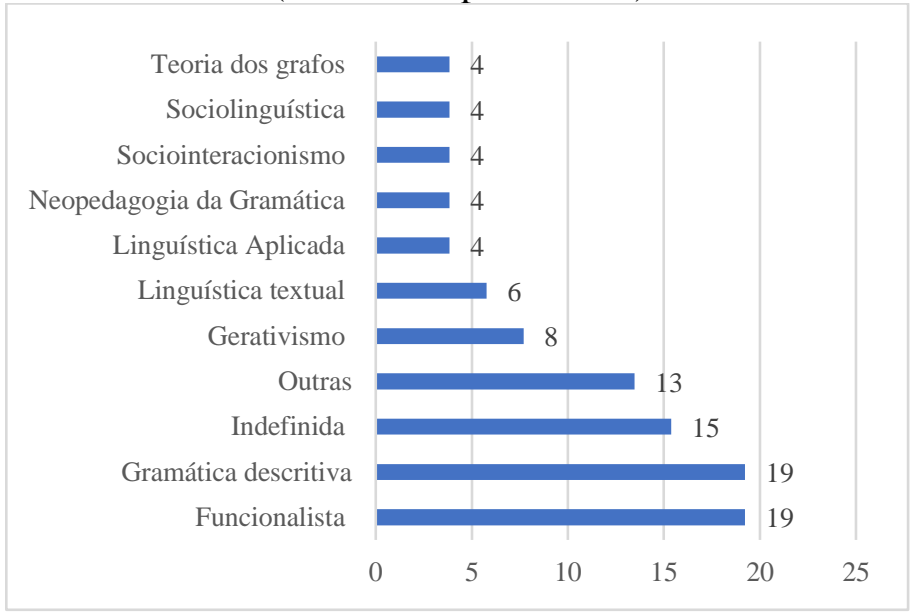

Fonte: Elaborado pelos autores

Por fim, identificou-se, nos trabalhos analisados, que a maior preocupação dos estudos sobre o ensino de sintaxe é explicitamente incrementar o que aqui denominamos de competências linguísticas dos alunos da educação básica brasileira $(\mathrm{n}=27)$. Essas pesquisas defendem um 
ensino de sintaxe em que se valorize o conhecimento das formas de estruturação do português e, em alguns casos, com o domínio da terminologia adequada para o tratamento dos fenômenos relacionados. Além dessa preocupação, é também expressiva a preocupação que o ensino de sintaxe possa contribuir para o aumento de competências de natureza textual, nomeadamente competências relacionadas à produção e compreensão textual $(n=19)$. A figura a seguir ilustra a distribuição das finalidades identificadas:

Figura 4. Distribuição das pesquisas conforme a finalidade do ensino de sintaxe (em valores percentuais)

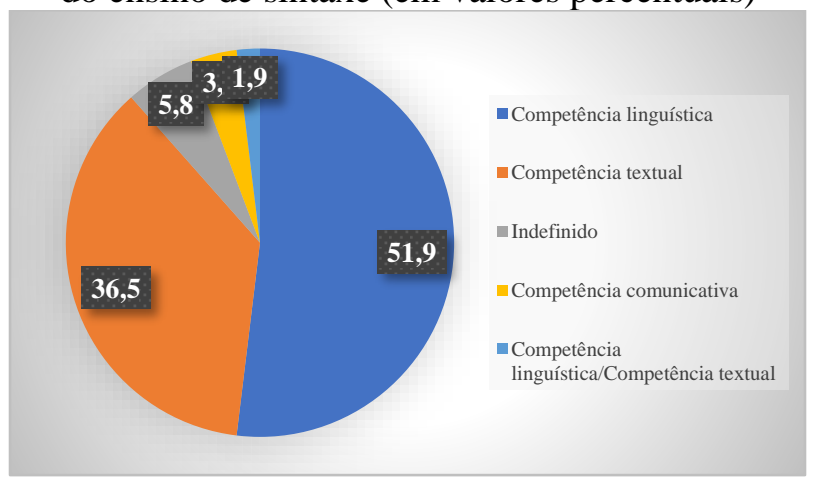

Fonte: Elaborado pelos autores

Como se nota na figura, é relevante que alguns estudos, embora numericamente inexpressivos, não materializam nos resumos a contribuição que o ensino de sintaxe que defendem possa trazer à educação $(n=3)$. Também são quantitativamente inexpressivos os estudos que apregoam que o ensino de sintaxe possa ter função na melhoria de competências comunicativas, vinculadas a questões de cidadania, por exemplo.

A seguir, discutimos sobre algumas das pesquisas no ensino de sintaxe que - julgamos - bem ilustram as categorias de análise até aqui apresentadas. As subseções que seguem se organizam a partir do tipo de abordagem investigativa identificada nos trabalhos em análise. 


\subsection{Abordagens propositivas}

A tese de doutorado de Sperança-Criscuolo (2011) é um estudo que objetiva apresentar uma descrição funcionalista-cognitivista de orações subordinadas substantivas para fins didático-pedagógicos. Para o estudo desse fato linguístico, a autora compilou um corpus com textos do tipo narrativo (romances, contos e notícias) e do tipo argumentativo (artigos de opinião, textos de divulgação científica e artigos acadêmicos). A pesquisadora defende que a sintaxe "constitui o eixo do texto, o ponto de encontro entre Falante e Ouvinte" (2011, p. 24). Essa tese se fundamenta na Gramática Discursivo-Funcional e na teoria cognitivista da Integração Conceptual. Por fim, Sperança-Criscuolo (2011, p. 28) conclui de seu estudo que "do ponto de vista do ensino de gramática - especificamente da sintaxe - acredita-se que o foco na funcionalidade destas orações pode tornar a prática em sala de aula mais rica e eficiente."

A pesquisa de Silva (2015) discute o processo de subordinação em construções completivas em períodos compostos do português na intenção de trazer uma contribuição para o ensino, descrevendo o desenvolvimento que diferentes livros didáticos apresentam ao longo de diferentes épocas e, ao mesmo tempo, trazendo sugestões de como o professor pode aproveitar esse material didático. $\mathrm{O}$ trabalho caracteriza-se por uma abordagem funcionalista e apresenta, em sua fundamentação, os estudos de Castilho (2012) e Neves (2001). Silva propõe uma abordagem mais significativa da sintaxe em sala de aula, a partir de uma discussão semântico-pragmática dessas orações.

Meada (2016) traz em sua dissertação de mestrado uma revisão crítica do processo sintático de subordinação substantiva, com o objetivo de apontar possíveis sugestões para a prática pedagógica. O corpus da pesquisa é constituído por três coleções didáticas dos anos finais do ensino fundamental, sendo confrontadas as informações contidas no manual destinado aos professores e a abordagem prática. A pesquisadora, fundamentada nos pressupostos da gramática descritiva de base funcionalista, constata que os materiais didáticos apresentam com maior frequência atividades de descrição e classificação de estruturas de maneira descontextualizada. Assim, direciona para o ensino uma proposta que foca nas funcionalidades das orações analisadas. 


\subsection{Abordagens diagnósticas}

Cortez (1999) investiga como a sintaxe é abordada nos livros didáticos de língua portuguesa. Tem como objetivo contemplar a sintaxe no âmbito do ensino de língua, acreditando que as concepções adotadas determinam a metodologia e a maneira de se trabalhar a sintaxe. Nesse estudo, foram analisados dois livros didáticos que adotam perspectivas diferentes. Um contempla a perspectiva tradicional e o outro contempla a perspectiva sociointeracionista. A pesquisa constata, a partir do exame de um dos livros, que existe uma resistência ao tradicionalismo no ensino de sintaxe, mas, ao comparar com o outro livro, identifica falhas. Sugere que a perspectiva inovadora do sociointeracionismo permite perceber como o modo tradicional é limitado para explicar os fatos sintáticos, bem como insuficiente para o desenvolvimento da competência comunicativa do aluno.

Em sua pesquisa, Costa e Barin (2003) analisam o tratamento dispensado à concordância verbal em questões de vestibular. Para o estudo desse fato linguístico, amparam-se nas orientações de gramáticas tanto normativas, como descritivas, sem deixar de explicitar que o tratamento que essas gramáticas propõem é marcado por incoerências, que podem ser minimizadas pela aproximação com gramáticas descritivas. Os autores criticam o abandono das questões sintáticas, em particular da concordância, dos sistemas de avaliação da educação básica, atribuindo a culpa desse abandono à complexidade do ensino de sintaxe atual, baseado em "normas e exceções" (COSTA; BARIN, 2003).

Bastos (2014), em sua dissertação de mestrado, investiga o fenômeno do desgarramento de orações hipotáticas circunstanciais em textos escolares. O desgarramento de orações, segundo a autora, é fenômeno cada vez mais recorrente na modalidade escrita do português brasileiro. $O$ estudo de Bastos, que se distingue dos outros aqui examinados por tratar do ensino de sintaxe no contexto da educação de jovens e adultos, toma como base para a descrição dessas orações os pressupostos da linguística sistêmicofuncional. O diagnóstico da autora se constrói a partir de um corpus composto por 825 textos de alunos, no quais se constata que certos usos linguísticos das desgarradas presentes nessas produções podem fazer sentido dentro do discurso em que estão inseridos, mas não se explicam pelas regras prescritas pela tradição gramatical, o que, de acordo com o autora, causa inquietação em muitos professores. 


\subsection{Abordagens interventivas}

Oliveira (2015), em sua dissertação de mestrado, aborda o ensino de sintaxe a partir de uma perspectiva estilístico-enunciativa. Traz uma proposta de intervenção para o ensino do período composto por coordenação e subordinação, aplicada em uma turma de $9^{\circ}$ ano do Ensino Fundamental. Seu trabalho objetiva, por meio da intervenção, discutir o ensino normativo da gramática e as possibilidades da linguagem enquanto processo de interação. Estudos bakhtinianos fundamentam a discussão teórica, que se complementa por pesquisa de campo. No estudo, critica-se que o ensino de sintaxe continua voltado para uma visão reducionista da língua para aspectos normativos e que essa visão ecoa em uma correspondência entre gramáticas, livros didáticos e prática docente. Defende, por fim, que trabalhar a sintaxe a partir da estilística como elemento constituinte do significado pode ser importante, pois que expõe a individualidade do sujeito na sua relação com o enunciado, o que permite a construção de gêneros textuais, e não de frases.

Xavier (2015) e Martins (2017), dissertações que se assemelham tanto no tema como na metodologia, analisam os usos de acusativo anafórico de terceira pessoa em produções narrativas escritas por alunos do $9^{\circ}$ ano do Ensino Fundamental e propõem estratégias de ensino. Ambos os estudos se fundamentam nos pressupostos sociolinguísticos e defendem que o acusativo anafórico, por sua importância na construção da textualidade, deve ser ensinado, o que, segundo os autores, não está acontecendo.

\section{Considerações finais}

Neste estado da arte, que tem por objetivo sistematizar a produção científica sobre o ensino de sintaxe no cenário brasileiro, identificamos que a abordagem de pesquisa mais recorrente é propositiva, fundamentada em análises de gramáticas, materiais didáticos, atividades diagnósticas e análise de corpus. A maioria dessas pesquisas justificam a análise de materiais didáticos pela facilidade do acesso e por ser o instrumento mais utilizado pelo professor em sala de aula. Essas pesquisas abordam os mais variados fatos sintáticos e lamentam que, apesar dos avanços nas pesquisas e nas diretrizes nacionais para o ensino de língua materna, ainda persistam práticas de memorização de regras, ignorando-se os usos reais. Apesar da importância dos achados propositivos e diagnósticos, constatamos que ainda 
são poucos os trabalhos sobre sintaxe e ensino que, além de defenderem propostas, também as testam, apontando para novos caminhos de como tratar a sintaxe em sala de aula. Vale a pena destacar o papel dos programas de pós-graduação na difusão de estudos de intervenções pedagógicas, como faz, por exemplo, o PROFLETRAS.

A sistematização aqui apresentada permite-nos concluir, por fim, que, apesar de fundamentadas em diferentes metodologias e teorias linguísticas, com diferentes abordagens investigativas e produzidas em diferentes épocas, as pesquisas sobre o ensino de sintaxe são convergentes em assinalar que esse ensino ainda é problemático na disciplina de Língua Portuguesa da educação básica brasileira, já que ainda se centra em gramáticas normativas e que, por essa razão, não se mostra significativo, sendo apenas um conjunto de regras e exceções que se vão acumulando ano a ano na vida escolar. É, portanto, um ensino que desconsidera que aprender conscientemente a sintaxe da língua tanto pode contribuir para o domínio da norma culta - enquanto o objetivo inflexível (e, arriscamo-nos, mítico!) que muitos ainda defendem -, como também pode estimular o pensamento científico dos alunos.

Por fim, é importante referir que, pelo recorte metodológico que assumimos neste estado da arte - e que entendemos ser uma limitação -, os resultados aqui expostos devem ser interpretados à luz do fato de alguns dos resumos selecionados nem sempre apresentarem todos os elementos retóricos considerados essenciais na sua composição textual. Outra limitação deste estudo é decorrente da seleção de descrições, que obviamente não consegue dar conta de toda a produção acadêmica relacionada ao ensino de sintaxe. Acreditamos que muitos trabalhos sobre fenômenos sintáticos em particular com contribuições significativas ao ensino possam não ter sido contemplados nas nossas buscas. Ambas as limitações apontam para possibilidades futuras. Se o ensino de sintaxe, ou da gramática, é pauta recorrente na esfera educacional ou das esferas a elas vinculadas, como é o caso da pesquisa científica, então não faltam motivos para que esse ensino seja recorrentemente discutido. 
Ensino de sintaxe na educação básica...

\section{Referências}

ALVES, H. N. O sujeito e a gramática: reflexões sobre a perspectiva funcional do ensino de português para o $5^{\circ}$ ano. Trabalho de Conclusão de Curso. (Graduação em Letras Português). Universidade Estadual da Paraíba, Centro de Educação, Campina Grande, 2018, 78p. Disponível em: <http://dspace.bc.uepb.edu.br/jspui/bitstream/123456789/17385/1/PDF\%20 -\%20Hermeson\%20Nobre\%20Alves.pdf > . Acesso em: 03 de junho de 2020.

BAGNO, M. Língua materna: letramento, variação e ensino. São Paulo: Parábola Editorial, 2003.

BRASIL. Lei de Diretrizes e Bases da Educação Nacional. Brasília: Ministério da Educação, 1996. Disponível em: <http://www.planalto.gov.br/ccivil 03/Leis/L9394.htm>. Acesso em: $10 \mathrm{de}$ junho de 2020.

BRASIL. Parâmetros Curriculares Nacionais: terceiro e quarto ciclos do ensino fundamental: língua portuguesa. Secretaria de Educação Fundamental. Brasília: Ministério da Educação, 1998. Disponível em: < http://portal.mec.gov.br/seb/arquivos/pdf/portugues.pdf $>$. Acesso em: $10 \mathrm{de}$ junho de 2020.

BRASIL. Base Nacional Comum Curricular: Educação Infantil, Ensino Fundamental e Ensino Médio. Brasília: MEC/Secretaria de Educação Básica, 2018. em: <http://basenacionalcomum.mec.gov.br/images/BNCC_EI_EF_110518_ver saofinal_site.pdf>. Acesso em: 10 de junho de 2019.

BASTOS, K. O. Trabalhando fora, estudando e cuidando da família: o desgarramento de cláusulas hipotáticas circunstanciais e seu status no ensino. Dissertação de Mestrado, Faculdade de Letras/UFRJ. Rio de Janeiro, 2014. $157 \mathrm{p}$.

CASTILHO, A. T. Nova gramática do português brasileiro. São Paulo: Editora Contexto, 2012. 
CORTEZ, S. Reflexão sobre a sintaxe em dois livros didáticos de língua portuguesa. Ao pé da letra, v. 1, p. 177-183, 1999.

COSTA, M. M.; BARIN, N. T. R. Sintaxe gerativa: Reflexões para a prática pedagógica da língua portuguesa. Disciplinarum Scientia, v. 4, n. 1, p. 125153, 2003.

COSTA, A.; BATALHA, J. Para um mapa das fronteiras e das pontes na investigação em didática da gramática. In: A linguística na Formação do Professor: das teorias às práticas. Porto: Universidade do Porto, 2019. p. 61-80.

FARACO, C. A.; CASTRO, G. Por uma teoria linguística que fundamente o ensino de língua materna: (ou de como apenas um pouquinho de gramática nem sempre é bom). Educar em Revista, Curitiba, v. 15, n. 15, p.109-129, jul./dez. 1999.

GONÇALVES, F. M. R. O conhecimento da Língua: percursos de desenvolvimento. 1. ed. Direção Geral de Inovação e de Desenvolvimento Curricular. Lisboa, 2011.

LIRA, L. S. A. As relações de predicação: uma proposta de análise linguística para o $7^{\circ}$ ano do Ensino Fundamental. Dissertação (mestrado). Programa de Pós-Graduação em Letras, Universidade Estadual do Piauí UESP, Teresina, 2018. 172p. Disponível em: <http://sistemas2.uespi.br:8080/bitstream/tede/144/5/Disserta\%C3\%A7\%C 3\%A3o_Texto\%20integral_LIRA\%2C\%20Luc\%C3\%A9lia\%20Saraiva\%2 0de\%20Abreu.pdf $>$. Acesso em: 03 de Junho de 2019.

MALFACINI, A. C. S. Breve histórico do ensino de Língua Portuguesa no Brasil: da Reforma Pombalina ao uso de materiais didáticos apostilados. Idioma, v. 28, p. 45-59, 2015.

MARTINS, M. A. Em defesa do ensino de gramática na escola. Revista do GELNE, v. 19, n. 1, p. 103-117, 25 maio 2017. Disponível em: <https://periodicos.ufrn.br/gelne/article/view/12117>. Acesso em: 03 de junho de 2019. 
Ensino de sintaxe na educação básica...

MARTINS, F. S. F. Termos oracionais na construção textual: o ensino de sintaxe além da metalinguagem. Dissertação. (Mestrado Profissional em Letras - PROFLETRAS), Universidade do Estado da Bahia. Departamento de Ciências Humanas. Campus V, Santo Antônio de Jesus, 2015.121p. Disponível em: < https://catalogodeteses.capes.gov.br/catalogo-teses/\#!/>. Acesso em: 03 de junho de 2019.

MEADA, D. B. G. O processo sintático de subordinação substantiva do livro didático: uma proposta de ensino produtivo das estruturas oracionais/ Débora Bianco Gonçalves Meada. Dissertação. (mestrado), Universidade do Estado de Rio de Janeiro, Instituto de Letras, Rio de Janeiro, 2016. 111p. Disponível em: < https://catalogodeteses.capes.gov.br/catalogo-teses/\#!/>. Acesso em: 03 de junho de 2019.

MELO, A. C. S. O apagamento das preposições antes de pronomes relativos introdutórios de orações subordinadas adjetivas. Dissertação. (Mestrado Profissional em Letras - PROFLETRAS), Universidade Estadual do Piauí UESPI, Teresina, 2016. 178p. Disponível em: <http://sistemas2.uespi.br:8080/bitstream/tede/109/5/DISSERTA\%C3\%87 $\%$ C3\%830\%20ANTONIO\%20CORRIGIDA\%20FINAL\%20\%20IMPRESS\%C3\%83O.pdf>. Acesso em: 03 de junho de 2019.

MENDES, A. V. M. Os complementos verbais no livro didático de língua portuguesa. In: ELENIN 2017 textos completos. VII Encontro de Estudos da Linguagem/ VI Encontro Internacional de Estudos da Linguagem: linguagens, instituições e práticas sociais. Pouso Alegre, 4 a 6 de outubro de 2017/ organização de Eni Puccinelli Orlandi... [et al.]. - Pouso Alegre: Univás, 2018.

MINAYO, M. C. S. (org.). Pesquisa Social. Teoria, método e criatividade. 18 ed. Petrópolis: Vozes, 2001.

MYHILL, D.; JONES, S.; LINES, H.; WATSON, A. Rethinking grammar: the impact of embedded grammar teaching on students writing and students metalinguistic understanding. Research Papers in Education, n. 27, v. 2, p. 139-166, 2012.

NEVES, M. H. M. A gramática funcional. São Paulo: Martins Fontes, 2001. 
OLIVEIRA, J. $O$ ensino de sintaxe em uma perspectiva estilísticoenunciativa: uma proposta para o ensino fundamental. Dissertação (Mestrado Profissional em Letras), Universidade Estadual da Paraíba, Centro de Humanidades, Guarabira-PB, 2015. 131p. Disponível em: $<$ http://tede.bc.uepb.edu.br/jspui/handle/tede/3113>. Acesso em: 3 de junho de 2019.

ROMANOWSKI, J. P.; ENS, R. T. As pesquisas denominadas do tipo "estado da arte" em educação. Diálogo Educacional, Curitiba, v. 6, n. 19, p. 39-40, dez. 2006.

SILVA, A. G. Orações modais: uma proposta de análise. Dissertação (Mestrado em Língua Portuguesa), Faculdade de Letras/UFRJ Rio de Janeiro, 2007, 140p.

SILVA, A. A. As Orações Principais em Construções Completivas do Português: uma contribuição para o ensino. Dissertação (Mestrado em Letras), Faculdade de Ciências e Letras, Universidade Estadual Paulista "Júlio de Mesquita Filho", Assis - SP, 2015. 119p. Disponível em: <https://repositorio.unesp.br/bitstream/handle/11449/136078/000854833.pd f? sequence $=1>$. Acesso em: 03 de junho de 2019 .

SPERANÇA-CRISCUOLO, A. C. Orações subordinadas substantivas sob uma perspectiva funcionalista-cognitivista: uma proposta de descrição e ensino. Tese (doutorado), Universidade Estadual Paulista, Faculdade de Ciências e Letras de Araraquara, 2011. 155p. Disponível em: <https://repositorio.unesp.br/bitstream/handle/11449/103544/criscuolo_acs _dr_arafcl.pdf?sequence=1>. Acesso em: 03 de junho de 2019.

XAVIER, A. C. M. Acusativo Anafórico e normas do português na escola: uma proposta de intervenção para o ensino de gramática. 2015. $127 \mathrm{f}$. Dissertação (mestrado) - Universidade Federal do Rio Grande do Norte. Centro de Ciências Humanas, Letras e Arte. Mestrado Profissional em Letras, Natal-RN, 2015. Disponível em: <https://repositorio.ufrn.br/jspui/bitstream/123456789/21361/1/AliceCarla MarcelinoXavier_DISSERT.pdf >. Acesso em: 03 de junho de 2019. 
Ensino de sintaxe na educação básica...

Submetido em: 16/09/2020

Aceito em: 07/12/2020

Title: The teaching of syntax in basic education: a state of the art in the Brazilian settings. 